\title{
Immunological classification of TRIC agents and of some recently isolated LGV agents by the micro-immunofluorescence test
}

\author{
J. D. TREHARNE, S. J. DAVEY, S. J. GRAY, AND B. R. JONES \\ Institute of Ophthalmology, University of London
}

Chlamydial isolates are conveniently divided on the basis of their ability to produce iodine staining material in their inclusion bodies, into the iodinepositive Subgroup A, which includes the trachomainclusion conjunctivitis (TRIC) agents and most isolates from lymphogranuloma venereum (LGV); and the iodine-negative Subgroup B, which includes isolations from psittacosis, ornithosis, and a wide variety of animal diseases.

Until recently, the main laboratory method for distinguishing LGV isolates from those of TRIC agent, has been the somewhat irregular ability of LGV agents to cause paralysis and subsequent death when inoculated intracerebrally into mice. Hence the labelling of isolates as LGV agents rather than TRIC agents has rested on their clinical origins. Furthermore, although it has been clear that TRIC isolates can be sub-divided, the difficulties and labour involved have limited these immunological studies to a few isolates.

Rake and Jones (1944) demonstrated the existence of a toxin associated with the elementary bodies of LGV which killed mice when inoculated intravenously. They later showed that this toxic factor could be neutralized by homologous anti-toxin produced in chickens, and that such a test could distinguish between LGV and psittacosis agents Using a similar test, Manire and Meyer (1950) were able to differentiate six main serotypes within the Subgroup B Chlamydia.

The more recent advances in differentiation of Subgroup A Chlamydia have resulted from the upsurge of research aimed at preventive vaccination against trachoma.

Bell, Snyder, and Murray (1959) demonstrated protection against the toxic factor of TRIC elementary bodies in mice that had been previously immunized with formalized suspensions of the agent. Using this technique they were able to divide TRIC agents into two distinct serotypes. This in vivo mouse toxicity prevention test (MTPT) was later

ead at a mceting of the MSSVD in November, 1970 confirmed by Chang, Wang, and Grayston (1962) and extended by Bell and Theobald (1962).

Nichols and McComb (1962) suggested the possibility of using a fluorescent antibody method for the serological differentiation of chlamydial agents. Nichols and McComb (1964) further developed this in vitro technique, basing their method on the absorption of trachoma antisera followed by indirect immunofluorescent staining of individual TRIC agent isolates. This test sub-divided TRIC agents into essentially the same two serotypes that had been demonstrated by the MTPT. Hanna and Bernkopf (1964) and Katzenelson and Bernkopf (1965), using a cross-absorbed direct immunofluorescent test, were able to confirm the existence of these two serotypes and to separate a Subgroup B chlamydial LGV isolate from those of TRIC agent, which are, of course, Subgroup A Chlamydia.

It became apparent, however, that there were a number of isolates, particularly those of genital origin, which did not fit into this two-serotype classification. Wang and Grayston (1963) and later Alexander, Wang, and Grayston (1967), employing a wide variety of Subgroup A Chlamydia, including many genital isolates from our laboratory, expanded the MTPT to six major serotypes. Types A, B, and $C$ were all isolates recovered from ocular tissues from cases in trachoma-endemic areas, whilst Types $\mathrm{D}, \mathrm{E}$, and $\mathrm{F}$ were mainly isolates from patients with chlamydial infection of the genital tract or genitally associated infection of the eye. At this time Bell and McComb (1967) added a further sub-type to Type 1 in their FA system which then became a threeserotype classification corresponding with Alexander's Types A, B, and C in the MTPT.

As a direct development from the MTPT, Wang and Grayston (1970) developed a new indirect microtitre immunofluorescent (micro-IF) typing test, which not only confirmed the existence of six major TRIC serotypes, but also extended the scope of the test by defining two new LGV serotypes from amongst ten Subgroup A chlamydial LGV isolates. Subsequently, Wang and Grayston (1971) reported 
that an LGV isolate provided from our laboratory (LGV/IOL-253/LN) did not exactly match either LGV Type I or Type II. Two Sub-group B chlamydial LGV isolates were serologically different from all the Subgroup A serotypes in this system.

We have confirmed Wang's findings, assessed the specificity of the differentiation between serotypes, and correlated them with the earlier direct crossabsorption immunofluorescent typing test (Treharne, Katzenelson, Davey, and Gray, 1971).

In a laboratory in which many chlamydial agents are being isolated from the genital tract and rectum as well as from the eye, the distinction between TRIC agent and LGV agents, which may not always be very clear-cut on a clinical basis (Jones, 1972), assumes considerable importance.

The present study was undertaken to assess the value of the micro-IF typing test as a practicable laboratory method of differentiating $\mathrm{LGV}$ isolates from TRIC isolates. This paper reports the results of serotyping a number of Subgroup A Chlamydia, some of which have been reported previously (Treharne and others, 1971; Wang and Grayston, 1970), and also a number of recently isolated Chlamydia from patients presenting with typical LGV, and confirms that the micro-IF test can indeed differentiate LGV isolates from TRIC isolates.

\section{MATERIALS}

The isolates used in this study have been grouped according to their country of origin and the laboratory supplying them; in some instances their more commonly used names follow their formal designations (Table IA, B). The full designation of isolates is after Gear, Gordon, Jones, and Bell (1963) with modification:

thus in TRIC $/ w / x / y / z$.

$\mathrm{w}$ indicates serotype or other biological classification, yet to be agreed.

$\mathbf{x}$ indicates geographic origin, as designated by international automobile licence plate.

$\mathrm{y}$ indicates laboratory and internal laboratory number of the isolate.

z indicates anatomical site of origin, with or without indication of clinical syndrome, e.g. trachoma, etc.

\begin{tabular}{|c|c|c|c|}
\hline Eye & Genital tract & Rectum & Lymph node \\
\hline$\overline{\mathrm{O}}$; eye & G; genital & R; & $\overline{\mathrm{LN} ;}$ \\
\hline $\begin{array}{l}\text { OC; eye, } \\
\text { TRIC } \\
\text { conjunctivitis }\end{array}$ & $\begin{array}{l}\text { GCx; genital, } \\
\text { cervix }\end{array}$ & & \\
\hline $\begin{array}{l}\text { OT; eye, } \\
\text { trachoma }\end{array}$ & $\begin{array}{l}\text { GU; genital, } \\
\text { urethra }\end{array}$ & & \\
\hline $\begin{array}{l}\text { OPK; eye, } \\
\text { trachoma } \\
\text { punctate } \\
\text { kerato-con- } \\
\text { junctivitis } \\
\text { (TPK) }\end{array}$ & $\begin{array}{l}\text { G Vag; genital, } \\
\text { vagina }\end{array}$ & & \\
\hline
\end{tabular}

TABLE I A Source of TRIC isolates studied

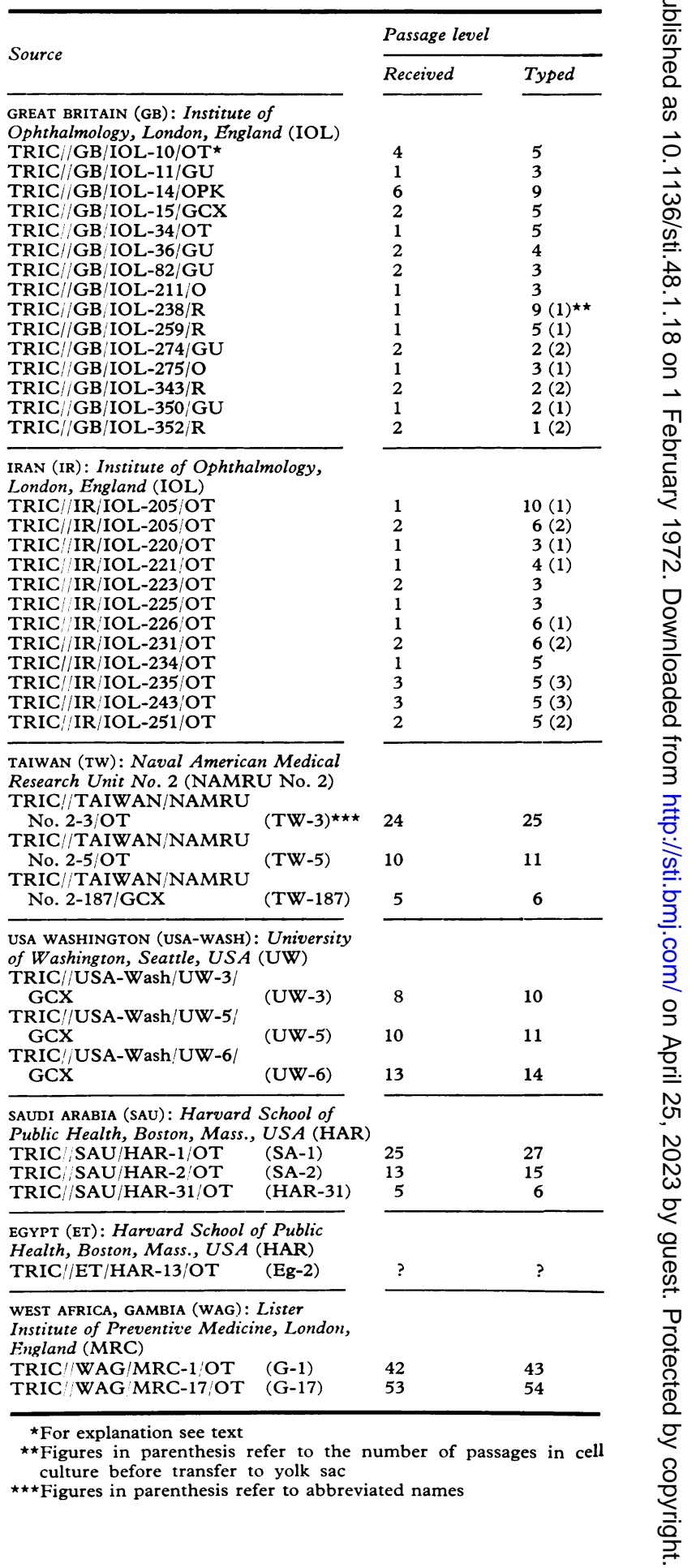


TA BLE I B Source of LGV isolates studied

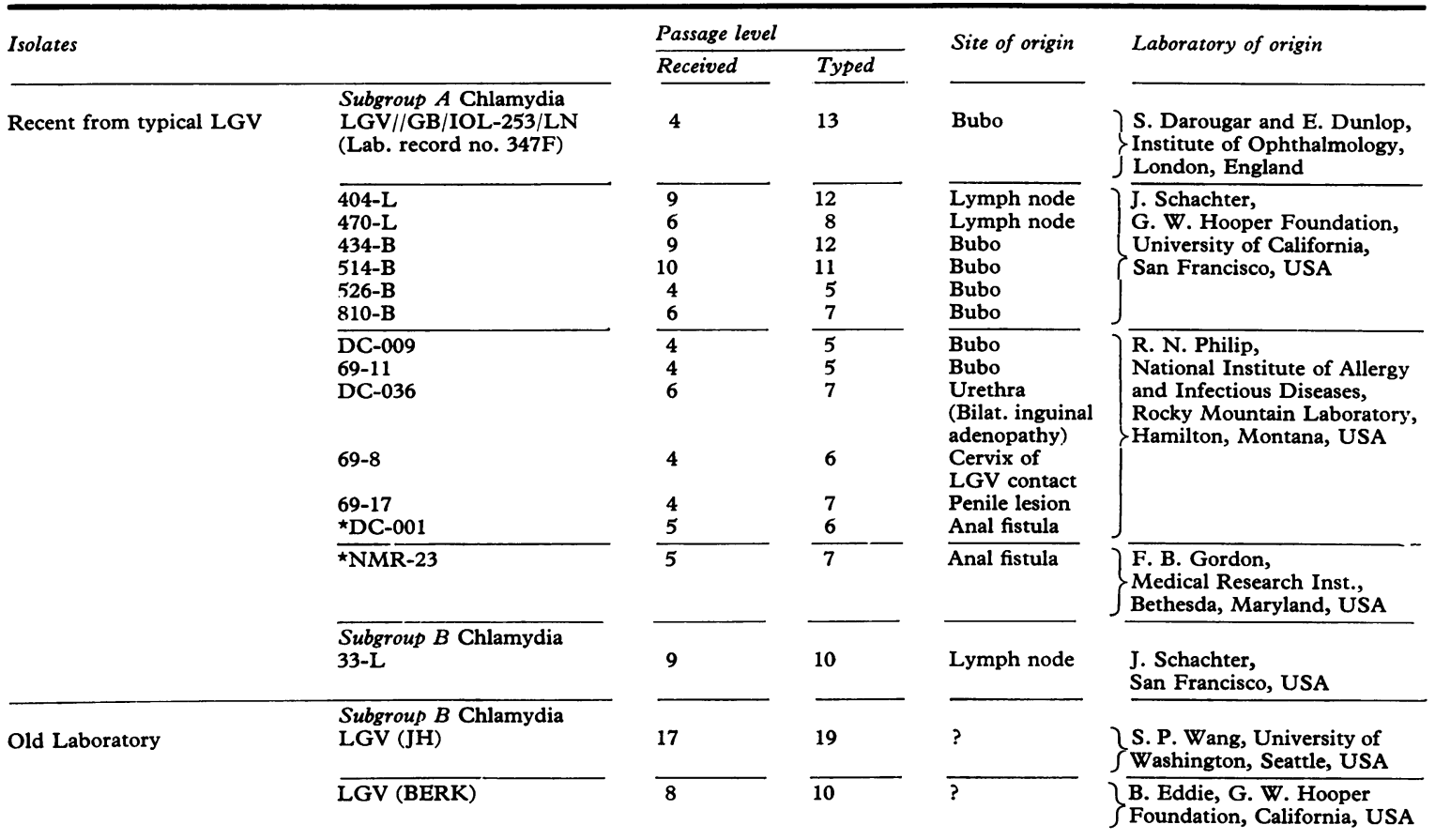

*Isolated from the same patient

In selecting the information to be included in an abbreviated version of the full designation it is most useful to give:

$\mathrm{x}$-geographic origin

$\mathrm{y}$-laboratory name and number of isolate

$\mathrm{z}$-anatomical site, and if known, the clinical syndrome present.

Thus: TRIC//GB/IOL-10/OT is conveniently abbreviated to $\mathrm{GB} / \mathrm{IOL}-10 / \mathrm{OT}$, indicating that it was isolated from the eye of a person with trachoma in Britain. When referring to an isolate internally within a laboratory by its number alone, the use of the laboratory prefix IOL serves to designate an isolate number from a specimen number or a culture code number.

\section{METHODS}

Detailed descriptions of the methods used in this study have been published in previous papers (Wang and Grayston, 1970; Treharne and others, 1971). Suffice it to indicate that, in the micro-IF test, immunizing antigens for the production of specific mouse antisera and antigens for the production of slide plaques are both prepared from strongly positive harvests grown in yolk sac. Each isolate being typed is titrated in a complete two-way cross-titration against its own antiserum and against antisera to all the known TRIC and LGV serotypes, which are in turn titrated against their homologous antisera and all the heterologous antisera, including the antiserum to the isolate being typed. Appropriate antigen (normal yolk sac) and antiserum (phosphate buffered saline) controls are included in each test. The significance of the results is assessed calculating the specificity differences (SPD) between strains using the formula of Fraser and Berman (1965).

\section{Results}

Of 53 Subgroup A Chlamydia that we have tested using the micro-IF technique only one has failed to fit Wang and Grayston's most recent classification of serotypes which includes three LGV serotypes. Of 25 ocular isolates studied all were typable: four have serotyped as Type $A$, four as Type $B$, ten as Type $C$, three as Type $D$, three as Type $E$, and one as Type F (Table II). All ocular isolates from trachoma endemic areas serotyped so far have been $\mathrm{A}, \mathrm{B}, \mathrm{C}$, or D. Those ocular isolates which have serotyped as Type $\mathrm{E}$ or $\mathrm{F}$ have come from areas where genital infection is common, and sexual transmission of the eye infection is presumed (Tables IA and IV).

Of a total of thirteen genital isolates tested, two serotyped as Type D, five as Type E, three as Type F, and three as LGV Type II (Table II).

Three out of four rectal isolates serotyped as Type 
TA B LE II Results of serotyping 53 Subgroup $A$ chlamydial isolates by the micro-IF test

\begin{tabular}{|c|c|c|c|c|c|c|c|c|c|c|c|}
\hline Site of origin & $A$ & $B$ & $C$ & $D$ & $E$ & $F$ & $L G V I$ & $L G V I I$ & $L G V I I I$ & $?$ & Total \\
\hline Genital & - & - & - & 2 & 5 & 3 & - & 3 & - & - & 13 \\
\hline Rectal & - & - & - & - & 3 & - & - & - & - & 1 & 4 \\
\hline Anal & - & - & - & - & - & - & - & 2 & - & - & 2 \\
\hline Lymph node & - & - & - & - & - & - & 1 & 6 & 2 & - & $\overline{9}$ \\
\hline
\end{tabular}

T A B LE I I I Specificity differences (SPD) between TRIC and LGV serotypes

\begin{tabular}{|c|c|c|c|c|c|c|c|c|c|}
\hline \multirow[t]{2}{*}{ Mouse antisera } & \multicolumn{9}{|c|}{ Slide antigens } \\
\hline & $C$ & $A$ & $F$ & $B$ & $E$ & $D$ & $L G V I$ & $L G V I I$ & $L G V I I I$ \\
\hline $\begin{array}{l}\text { C } \\
\text { A }\end{array}$ & $\begin{array}{l}0 \\
4\end{array}$ & $\begin{array}{l}4 \\
0\end{array}$ & $\begin{array}{l}10 \\
10\end{array}$ & $\begin{array}{l}10 \\
11\end{array}$ & $\begin{array}{r}9 \\
10\end{array}$ & $\begin{array}{l}11 \\
12\end{array}$ & $\begin{array}{l}12 \\
12\end{array}$ & $\begin{array}{r}12 \\
9\end{array}$ & $\begin{array}{l}13 \\
13\end{array}$ \\
\hline $\begin{array}{l}\mathrm{F} \\
\mathrm{B}\end{array}$ & $\begin{array}{l}10 \\
10\end{array}$ & $\begin{array}{l}10 \\
11\end{array}$ & $\begin{array}{r}0 \\
11\end{array}$ & $\begin{array}{r}11 \\
0\end{array}$ & $\begin{array}{l}8 \\
6\end{array}$ & $\begin{array}{l}9 \\
6\end{array}$ & $\begin{array}{r}9 \\
10\end{array}$ & $\begin{array}{r}8 \\
11\end{array}$ & $\begin{array}{r}8 \\
13\end{array}$ \\
\hline $\begin{array}{l}\mathrm{E} \\
\mathrm{D}\end{array}$ & $\begin{array}{r}9 \\
11\end{array}$ & $\begin{array}{l}10 \\
12\end{array}$ & $\begin{array}{l}8 \\
9\end{array}$ & $\begin{array}{l}6 \\
6\end{array}$ & $\begin{array}{l}0 \\
2\end{array}$ & $\begin{array}{l}2 \\
0 \\
0\end{array}$ & $\begin{array}{l}5 \\
5\end{array}$ & $\begin{array}{l}74 \\
4\end{array}$ & $\begin{array}{l}3 \\
4 \\
4\end{array}$ \\
\hline
\end{tabular}

T A BLE IV Chlamydia Subgroup A TRIC isolates serotyped by the micro-IF test

\begin{tabular}{|c|c|c|c|c|c|}
\hline \multicolumn{6}{|l|}{ Serotype } \\
\hline WAG/MRC-17 OT & $\begin{array}{l}\text { Taiwan NAMRU } \\
\text { No. } 2-5 / O T\end{array}$ & $\begin{array}{l}\text { Taiwan/NAMRU } \\
\text { No. 2-3/OT }\end{array}$ & $\begin{array}{l}\text { USA-Wash/UW-3/ } \\
\text { GCX }\end{array}$ & $\begin{array}{l}\text { USA-Wash/UW-5! } \\
\text { GCX }\end{array}$ & $\begin{array}{l}\text { USA-Wash/UW-6/ } \\
\text { GCX }\end{array}$ \\
\hline ET/HAR-13/OT & SAU/HAR-2/OT & IR/IOL-205/OT & GB/IOL-10/OT & $\begin{array}{l}\text { Taiwan/NAMRU } \\
\text { No. 2-187/GCX }\end{array}$ & GB/IOL-14/OPK \\
\hline $\begin{array}{l}\text { SAU/HAR-1/OT } \\
\text { SAU/HAR-31/OT }\end{array}$ & $\begin{array}{l}\text { IR/IOL-243/OT } \\
\text { IR/IOL-251/OT }\end{array}$ & $\begin{array}{l}\text { IR/IOL-206/OT } \\
\text { IR/IOL-220/OT } \\
\text { IR/IOL-221/OT } \\
\text { IR/IOL-223/OT } \\
\text { IR/IOL-225/OT } \\
\text { IR/IOL-226/OT } \\
\text { IR/IOL-231/OT } \\
\text { IR/IOL-234/OT }\end{array}$ & $\begin{array}{l}\text { GB/IOL-11/GU } \\
\text { IR/IOL-235/OT } \\
\text { WAG/MRC-1/OT }\end{array}$ & $\begin{array}{l}\text { GB/IOL-34/OT } \\
\text { GB/IOL-36/GU } \\
\text { GB/IOL-211/O } \\
\text { GB/IOL-259/R } \\
\text { GB/IOL-274/GVag } \\
\text { GB/IOL-275/O } \\
\text { GB/IOL-343/R } \\
\text { GB/IOL-350/GU } \\
\text { GB/IOL-352/R }\end{array}$ & $\begin{array}{l}\text { GB/IOL-15/GCX } \\
\text { GB/IOL-82/GU }\end{array}$ \\
\hline
\end{tabular}

E, the other, TRIC//GB/IOL-238/R, was untypable.

Two LGV isolates, made in different laboratories from the anal fistula of one patient, both serotyped as LGV Type II, and of a total of nine lymph node or bubo isolates, one serotyped as LGV Type I, six as LGV Type II, and two as LGV Type III (Table VII).

In addition to the one Subgroup A Chlamydia which the micro-IF test indicated as serologically different from TRIC types, A, B, C, D, E, and F, two old laboratory Subgroup B chlamydial LGV isolates, and a further two Subgroup B agents of animal origin were clearly distinguished from the Subgroup A isolates by this test.

Mean specificity differences (SPD) and inter- relationships between TRIC and LGV serotypes are shown in Table III.

The classification of 38 TRIC agent isolates which were typed by the micro-IF test is shown in Table IV. One TRIC isolate (GB/IOL-238/R) could not be serotyped by the existing micro-IF classification.

The results of serotyping pairs of isolates from different bodily sites in individual patients are shown in Table $\mathrm{V}$ (overleaf).

Titres of cross-reactions and SPD between certain LGV isolates are shown in Table VI (overleaf).

The micro-IF immunological classification of the LGV isolates examined in this study is shown in Table VII (overleaf). 
TABLE V Results of serotyping three 'paired' isolates

\begin{tabular}{|c|c|c|c|}
\hline $\begin{array}{l}\text { Patient's } \\
\text { code }\end{array}$ & $\begin{array}{l}\text { Isolate } \\
\text { designation }\end{array}$ & $\begin{array}{l}\text { Site of } \\
\text { origin }\end{array}$ & $\begin{array}{l}\text { Micro-IF } \\
\text { type }\end{array}$ \\
\hline Mr. S. & $\left\{\begin{array}{l}\text { GB/IOL-10/OT } \\
\text { GB/IOL-11/GU }\end{array}\right.$ & $\begin{array}{l}\text { Conjunctiva } \\
\text { Urethra }\end{array}$ & $\begin{array}{l}\text { D } \\
\text { D }\end{array}$ \\
\hline Miss A. B. & $\left\{\begin{array}{l}\text { GB/IOL-14/OPK } \\
\text { GB/IOL-15/GCX }\end{array}\right.$ & $\begin{array}{l}\text { Conjunctiva } \\
\text { Cervix }\end{array}$ & $\begin{array}{l}F \\
F\end{array}$ \\
\hline Mr. B. L. & $\left\{\begin{array}{l}\text { GB/IOL-34/OT } \\
\text { GB/IOL-36/GU }\end{array}\right.$ & $\begin{array}{l}\text { Conjunctiva } \\
\text { Urethra }\end{array}$ & $\begin{array}{l}\mathrm{E} \\
\mathrm{E}\end{array}$ \\
\hline
\end{tabular}

\section{Discussion}

The ocular TRIC agent isolates studied have fallen into each of the six TRIC micro-IF serotypes A, B, C, D, E, or F. TRIC agent isolates from the genital tract and rectum have, however, serotyped only as D, E, or F types, apart from GB/IOL-238/R, which appears to represent a new TRIC serotype.

All TRIC agent isolates from eye disease in London that we have so far tested, have serotyped as $\mathrm{D}, \mathrm{E}$, or $\mathrm{F}$, whereas all isolates originating from trachoma-endemic areas have serotyped as $\mathrm{A}, \mathrm{B}$, or $C$, apart from two that are $D$. In trachoma-endemic or 'oriental' trachoma areas, there is a high prevalence of eye disease and the majority of transmission is probably from eye to eye. Whereas in 'occidental' trachoma acquired in Britain, the incidence of such eye disease is low and it is likely that most of the transmission occurs via the genital tract with genitalto-eye transfer. It is of interest, however, that two ocular isolates from typical endemic trachoma, WAG/MRC-1/OT or G-1 from the Gambia, and IR/IOL-235/OT from Iran, both typed as $D$, a serotype normally associated with genital transmission. This finding might suggest that isolates from classical 'oriental' trachoma, of eye-to-eye transmission, are not just confined to serotypes A, B, and C, but sometimes include also serotype D;
TABLE VI I Chlamydia Subgroup $A$ LGV isolates serotyped by micro-IF test

\begin{tabular}{|c|c|c|}
\hline \multicolumn{3}{|l|}{ Serotype } \\
\hline$L G V I$ & $L G V I I$ & $L G V I I I$ \\
\hline 810-B & $\begin{array}{l}470-\mathrm{L} \\
434-B \\
514-B \\
526-B \\
\text { NMR-23 } \\
\text { DC-001 } \\
\text { DC-009 } \\
\text { DC-036 } \\
69-8 \\
69-11 \\
69-17\end{array}$ & $\begin{array}{l}\text { 404-L } \\
\text { LGV } / / G B / \text { IOL-253/LN* }\end{array}$ \\
\hline
\end{tabular}

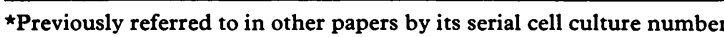
347-F.

or alternatively that a level of genital transmission does occur in those areas where there is a high prevalence of ocular infection, of probable eye-to-eye transmission. Sowa, Sowa, Collier, and Blyth (1965) have isolated TRIC agents from the genital tract of patients in the Gambia where the type D ocular isolate WAG/MRC-1/OT was made, and one of these genital isolates, WAG/MRC-301/GU, has been shown by Wang and Grayston (1970) to immunotype as micro-IF type F. We have not so far attempted to isolate TRIC agent from the genital tracts of patients in Iran in order to evaluate the possibility of genital infection and sexual transmission of trachoma in this area.

Three pairs of isolates from different bodily sites in individual patients were examined in this study (Table V). In every instance the serotype of each isolate of the 'pair' was identical to that of its partner. It is of interest that our micro-IF type $F$ isolates GB/IOL-14/OPK from the eye and GB/IOL-15/ GCX from the cervix of Miss $A B$ had both previously been typed by Alexander and others (1967) in the

T A B L E V I Specificity differences between certain LGV isolates

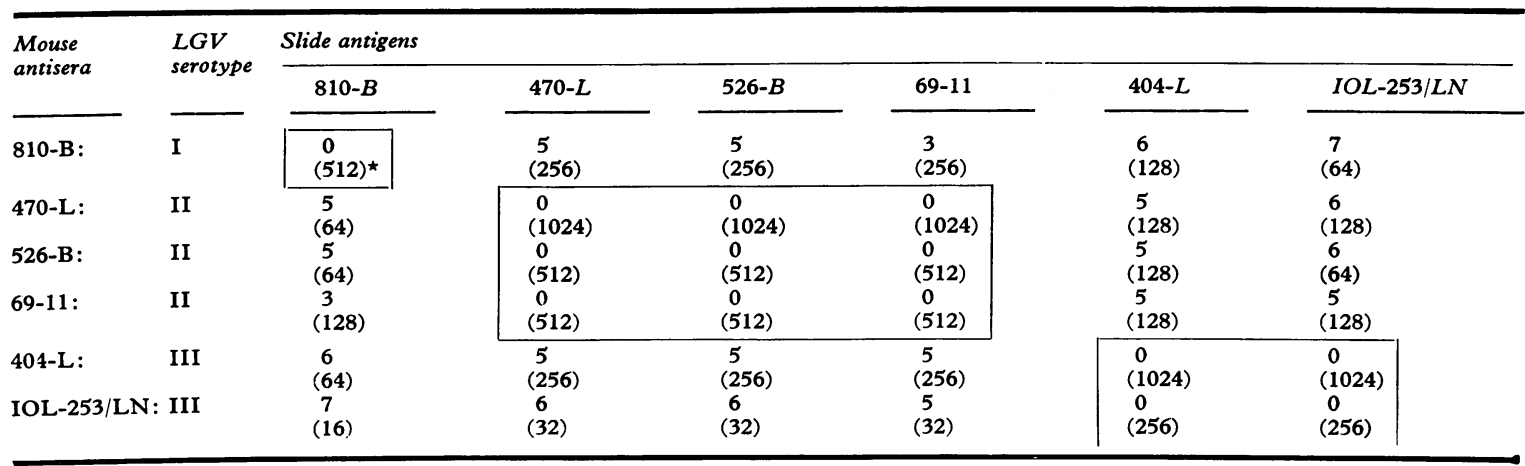

* Figures in parenthesis represent reciprocal titres of cross-reactions 
MTPT as Type $F$, thus providing confirmation of the results and of the concordance of the two typing systems. These results indicate that the same serotype is responsible for both eye and genital disease, even when the eye condition is trachoma, as in the cases of Mr. S. and Mr. B.L., and support the belief that sexual transmission with genital-to-eye transfer are important factors in the spread of these diseases, at least in certain areas.

In an earlier study we had not been able (because of insufficient data) unequivocally to differentiate between the $\mathrm{D}$ and $\mathrm{E}$ serotypes, so we had indicated these isolates as belonging to the $\mathrm{D} / \mathrm{E}$ complex (Treharne and others, 1971). However, we suggested that by using 4-day mouse antisera, more clear-cut specificity differences between these two serotypes could be demonstrated. The validity of this finding has been further substantiated, although the usefulness of such 4-day antisera is limited by their lower stability at sub-zero temperatures than the conventional 10-day mouse antisera.

We have now carried out numerous duplicate two-way cross-titrations between isolates in the $\mathrm{D} / \mathrm{E}$ complex; these indicate a mean SPD between these serotypes of $2 \cdot 4$; this difference was found to be significant at the $\mathbf{P}<0.05$ level. Accordingly, we have now been able to differentiate into their individual serotypes all isolates previously labelled ' $D / E$ complex' (Table IV). Other close relationships were shown between TRIC E, D, LGV I, LGV II, and LGV III types and between TRIC $A$ and $C$ serotypes.

In the present study we have typed a Subgroup A chlamydial isolate, LGV//GB/IOL-253/LN, secured in this laboratory by Dr. S. Darougar from material aspirated by Dr. E. M. C. Dunlop from an enlarged lymph node of a patient who presented at the Whitechapel Clinic of The London Hospital with typical LGV.

The findings with this isolate have been compared with observations made on a number of other recent isolates made from typical LGV, in the District of Columbia, USA, kindly supplied by Drs. R. Philip and F. B. Gordon (Philip, Hill, Greaves, Gordon, Quan, Gerloff, and Thomas, 1971) and the San Francisco area kindly supplied by Dr. J. Schachter (Schachter and Meyer, 1969; Schachter, Smith, Dawson, Anderson, Deller, Hoke, Smartt, and Meyer, 1969). We have also examined two old laboratory strains of LGV agents (Table Ib).

All the LGV isolates other than 33-L, and the two old laboratory strains LGV (JH) and LGV (Berk), produced iodine-positive inclusions when grown in irradiated McCoy cell cultures and were accordingly classified as members of the Subgroup A
Chlamydia (Table Ib). In the micro-IF test all these Subgroup A chlamydial isolates were serotyped as either LGV Type I, LGV Type II, or LGV Type III (Table VII). Two isolates including one from London (LGV//GV/IOL-253/LN) and one from San Francisco 404-L immunotyped as LGV Type III and eleven isolates including seven from the District of Columbia and four from San Francisco immunotyped as LGV Type II.

The isolate 810-Bu from San Francisco has been classified by Wang and Grayston (1971) as LGV Type I. This isolate is the only Type I LGV isolate available to us and our tests have indicated that it is related to but different from LGV Types II and III (Table VI).

The three LGV types are clearly differentiated from the six TRIC immunotypes, although they all showed a relationship with the TRIC D and E serotypes (Table III).

Isolates NMR-23 and DC-001 were obtained from the anal fistula of the same patient (Table Ib), NMR-23 being isolated in cell culture in Dr. Gordon's laboratory and DC-001 being isolated in yolk sac in Dr. Philip's laboratory. Both isolates serotyped as LGV Type II (Table VII), thus giving no indication that primary isolation in cell culture selects out or alters the serotype of the agent.

It is of note that the results in our laboratory with the micro-IF test are in agreement with the results obtained elsewhere in the cases of isolates of either TRIC or LGV agents previously typed either by Wang and Grayston (1971) in the micro-IF test or by Alexander and others (1967) in the MTPT. The single exception to this conformity is LGV// GB/IOL-253/LN (sometimes referred to by its serial cell culture number LGV 347-F) which Wang and colleagues could not classify as LGV I or II, using 440-L and 434-B as reference strains (Wang and Grayston, 1971). In our hands it behaved as a typical LGV Type I isolate, using 404-L as the reference strain (Treharne and others, 1971). With Wang's re-designation of 404-L as LGV Type III, our isolate LGV//GB/IOL-253/LN now becomes LGV Type III, and there is complete agreement between the two laboratories.

The importance and increasing recognition of TRIC agent as a causative organism in non-specific genital infection has been well documented by Darougar, Dwyer, Treharne, Harper, Garland, and Jones (1971) and Jones (1972). Previously used insensitive mouse pathogenicity tests, delayed hypersensitivity skin reactions such as the Frei test, and complement-fixation tests which measure antibody predominantly to shared group antigens, have failed satisfactorily to differentiate LGV from TRIC agents. 
This differentiation has therefore had to rest on the clinical description of the disease from which the isolate was obtained; in some cases this may be difficult (Jones, 1972). Schachter and Meyer (1969) have suggested that LGV may be produced by a wide variety of chlamydial agents, and that the variation in the various biological characteristics of these isolates forms a broad spectrum; some being Subgroup A and others being Subgroup B Chlamydia . The present results indicate that all but one (33-L) of the agents isolated from recent cases of LGV are Subgroup A Chlamydia and can be immunologically differentiated from TRIC, by falling into one of Wang and Grayston's three distinct LGV serotypes.

The Subgroup B chlamydial isolates from LGV are widely separated from the Subgroup A isolates in the micro-IF test and are, of course, readily differentiated from TRIC agent on other biological characteristics. The interrelations between the Subgroup B isolates from LGV, those from Reiter's disease, and those isolated from diseased birds or animals require further elucidation, especially with micro-IF typing, as does their role in pathogenesis and epidemiology of human disease of the eye, genital tract, and articular systems.

\section{Summary}

A total of 53 Subgroup A Chlamydia have been serotyped using the two-way cross titration indirect micro-immunofluorescence test (micro-IF) of Wang and Grayston (1970). All but one isolate were typed and the test clearly divided TRIC agents from LGV agents. TRIC agents were further sub-divided into six serological types, and LGV agents into three serotypes.

The ocular isolates from trachoma in trachomaendemic areas generally serotyped as A, B, or C, apart from one from the Gambia, and one from Iran that typed as D. Ocular isolates from trachoma and other syndromes of TRIC agent infection of the eye in London, on the other hand, serotyped as D, E, or F. All genital TRIC agent isolates serotyped as $D, E$, or $F$, and three out of four rectal isolates serotyped as $E$; the remaining isolate TRIC//GB/ IOL-238/R appears to represent a new TRIC serotype. Of fifteen Chlamydia recently isolated from typical cases of LGV, one serotyped as LGV Type I, eleven as LGV Type II, and two as LGV Type III; the only one which failed to serotype was shown to be a Subgroup B Chlamydia. There was complete agreement between the results in this study, with those from other laboratories in all cases of isolates previously typed in the micro-IF test by Wang, or in the MTPT by Alexander, when considered in the light of Wang and Grayston's re-classification including three LGV serotypes.

The micro-IF typing test thus provides a practicable, reproducible, and highly incisive method of identifying TRIC agents and LGV agents, and of sub-dividing TRIC and LGV agents into serotypes that correlate with epidemiological features.

\section{References}

Alexander, E. R., WANG, S. P., and Grayston, J. T. (1967) Amer. F. Ophthal., 63, 1469

Bell, S. D., Jr., and McComb, D. E. (1967) Proc. Soc. exp. Biol. (N.Y.), 124, 34

-, SNyder, J. C., and Murray, E. S. (1959) Science, 130, 626

- and Theobald, B. (1962) Ann. N.Y. Acad. Sci., 98, 337

Chang, I. G., Wang, S. P., and Grayston, J. T. (1962) Ibid., 98, 347

Darougar, S. D., Dwyer, R. St. C., Treharne, J. T., Harper, I. A., Garland, J. A., and Jones, B. R. (1971) In 'Trachoma and Allied Diseases, 1970', ed. R. L. Nichols. Excerpta Medica, Amsterdam and New York. I.C.S. No. 223, p. 445

Fraser, C. E. O., and BERMAN, D. T. (1965) F. Bact., 89, 943

Gear, J. H. S., Gordon, F. B., Jones, B. R., and Bell, S. D. (1963) Nature (Lond.), 197, 26

Hanna, L., and Bernkopf, H. (1964) Proc. Soc. exp. biol. (N.Y.), 116, 827

JoNEs, B. R. (1972) Brit. f. vener. Dis., 48, 13

KATZENELSON, E., and BeRNKOPF, H. (1965) $\mathcal{f}$. Immunol., 94, 467

Manire, G. P., and Meyer, K. F. (1950) F. infect. Dis., 86,226

Nichols, R L., and McСомв, D. E. (1962) f. Immunol., 89, 545

- (1964) F. exp. Med., 120, 639

Philip, R. N., Hill, D. A., Greaves, A. B., Gordon, F. B., QuAN, A. L., GerlofF, R. K., and Thomas, L. A. (1971) Brit. F. vener. Dis., 47, 114

RAKe, G., and Jones, H. P. (1944) f. exp. Med., 79, 463 SCHACHTER, J., and MEYER, K. F. (1969) F. Bact., 99, 636 -, Smith, D. E., Dawson, C. R., Anderson, W. R., Deller, J. J., Jr., Hoke, A. W., SmartT, W. H., and MEYeR, K. F. (1969) J. infect. Dis., 120, 372

Sowa, S., Sowa, J., Collier, L. H., and Blyth, W. (1965) M.R.C. Spec. Rep. Ser. No. 308, H.M.S.O., London.

Treharne, J. D., Katzenelson, E., Davey, S., and GRAY, S. (1971) In 'Trachoma and Allied Diseases, 1970', ed. R. L. Nichols. Excerpta Medica, Amsterdam and New York. I.C.S. No. 223, p. 289

WANG, S. P., and Grayston, J. T. (1963) F. Immunol., 90, 549

- (1970) Amer. F. Ophthal., 70, $3 \leqslant 7$.

(1971) In 'Trachoma and Allied Diseases, 1970', ed. R. L. Nichols. Excerpta Medica, Amsterdam and New York. I.C.S. No. 223, p. 305 
Classification immunologique, par l'épreuve de la micro-immunofluorescence, des agents du groupe TRIC et de quelques agents du groupe LGV récemment isolés

\section{SOMMAIRE}

On a établi le séro-type de 53 Chlamydia du sous-groupe A en utilisant le test de titration croisée en deux étapes ${ }^{\star}$ en micro-immunofluorescence indirecte (Micro-IF) de Wang et Grayston (1970). Tous les spécimens isolés, sauf un, furent typés et le test distingua nettement les agents TRIC des agents LGV. Les agents TRIC furent ultérieurement subdivisés en six types sérologiques et les agents LGV en trois séro-types.

Les spécimens isolés de l'oeil, dans le trachome ou dans les régions d'endémie trachomateuse, furent généralement séro-typés comme $\mathrm{A}, \mathrm{B}$, ou $\mathrm{C}$, sauf un provenant de Gambie et un autre provenant d'Iran, typés comme D. D'autre part, les spécimens oculaires isolés, à Londres, de cas de trachome ou d'autres syndromes d'infection des yeux par agents TRIC, furent séro-typés comme D,E,F. Tous les agents TRIC d'origine génitale furent séro-typés comme D,E,F, et trois des autres spécimens isolés du rectum furent séro-typés comme $\mathrm{E}$; le dernier spécimen TRIC/GB/IOL-238/R semble représenter un nouveau séro-type TRIC. Sur 15 Chlamydia récemment isolés de cas typiques de LGV, un fut séro-typé comme LGV type I, onze comme LGV type II et deux comme LGV type III. Le seul qui ne put être typé se montra être un Chlamydia du sous-groupe B. Les résultats de cette étude ont été en complet accord avec ceux d'autres laboratoires pour tous les spécimens antérieurement typés par le test de micro-IF par Wang ou par le MTPT ${ }^{\star \star}$ par Alexander, si l'on adopte la nouvelle classification de Wang et Grayston comprenant trois séro-types LGV.

Le test de typage par micro-IF constitue ainsi une méthode pratique, reproductive et à réponses nettement tranchées pour identifier les agents TRIC et LGV et pour subdiviser ces agents TRIC ou LGV en séro-types qui correspondent aux faits épidémiologiques.

$\star$ Voir texte (N.d.T.)

$\star \star$ Mouse Toxicity Prevention Test, épreuve de protection de la souris (N. de T.) 